\title{
Cost5-97/234-
}

32 . LA-UR- 9 ry -4732

Title:

Second Annual Review Update

Preliminary Risk Assessment of Federally Protected Species at the Los Alamos

National Laboratory

\section{DTIC QUALTTY INSPECTED 2}

Submitted to:

Annual Review of the Threatened and Endangered Species Habitat Management Plan at Los Alamos National Laboratory 2 December 1997

\section{7}

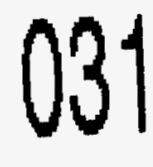

DISTRIBUTION OF THIS DOCUMENT IS UNLIMITED
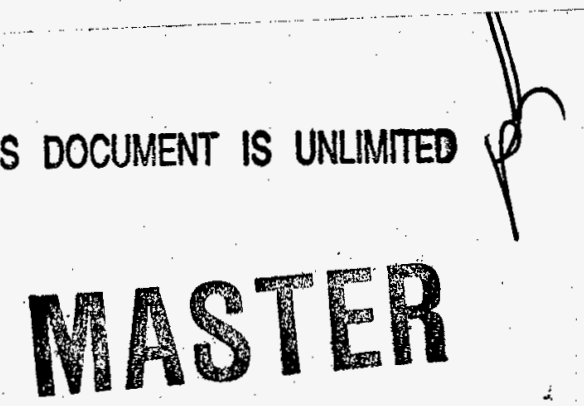

\section{Los Alamos}

NATIONALLABORATORY

Los Alamos National Laboratory, an affirmative action/equal opportunity employer, is operated by the University of California for the U.S. Department of Energy under contract W-7405-ENG-36. By acceptance of this article, the publisher recognizes that the U.S. Government retains a nonexclusive, royalty-free license to publish or reproduce the published form of this contribution, or to allow others to do so, for U.S. Government purposes. Los Alamos National Laboratory requests that the publisher identify this article as work performed under the auspices of the U.S. Department of Energy. The Los Alamos National Laboratory strongly supports academic freedom and a researcher's right to publish; as an institution, however, the Laboratory does not endorse the viewpoint of a publication or guarantee its technical correctness. 


\section{DISCLAIMER}

This report was prepared as an account of work sponsored by an agency of the United States Government. Neither the United States Government nor any agency thereof, nor any of their employees, makes any warranty, express or implied, or assumes any legal liability or responsibility for the accuracy, completeness, or usefulness of any information, apparatus, product, or process disclosed, or represents that its use would not infringe privately owned rights. Reference herein to any specific commercial product, process, or service by trade name, trademark, manufacturer, or otherwise does not necessarily constitute or imply its endorsement, recommendation, or favoring by the United States Government or any agency thereof. The views and opinions of authors expressed herein do not necessarily state or reflect those of the United States Government or any agency thereof. 


\title{
Second Annual Review Update \\ Preliminary Risk Assessment of Federally Listed Species \\ at the Los Alamos National Laboratory
}

Gilbert J. Gonzales, Anthony F. Gallegos, and Teralene S. Foxx

\begin{abstract}
In FY96 and FY97, preliminary assessments were conducted of the potential risk from legacy waste to the American peregrine falcon (Falco peregrimus), the bald eagle (Haliaeetus leucocephalus), and the Mexican spotted owl (Strix occidentalis lucida). Estimated doses were compared against toxicity reference values (TRVs) to generate hazard indices that included a measure of cumulative effects from multiple contaminants (radionuclides, metals, and organic chemicals). The tools used included a custom FORTRAN code ECORSK, and a geographic information system. The assessments originally included only the soil ingestion contaminant pathway. Since the initial assessments, a food consumption contaminant pathway has been added, bioaccumulation and biomagnification of some contaminants have been factored into the food consumption pathway, and some of the TRVs against which estimated doses are compared have been changed to values which relate more closely to the Aves taxonomical class. With these and other more subtle improvements in model input parameters, ECORSK has been revised and the model has been re-executed for the owl and peregrine exposure units that originally generated the highest risk indices. This report contains the updated results. On average, results indicate a small potential for impact to the peregrine falcon, but no appreciable impact to the spotted owl nor the bald eagle. The original reports cited in this document should be consulted for details on methods.
\end{abstract}

\section{Introduction and Background}

In FY96 and FY97, preliminary assessments were conducted of the potential risk from legacy waste to the Mexican spotted owl (Strix occidentalis lucida) (Gallegos et al. 1997a), the American peregrine falcon (Falco peregrimus) (Gallegos et al. 1997b), and the bald eagle (Haliaeetus leucocephalus) (Gonzales et al. 1997). Estimated doses were compared against toxicity reference values (TRVs) to generate hazard indices (HIs) that included a measure of cumulative effects from multiple contaminants (radionuclides, metals, and organic chemicals). Considering the objectives of the original assessments and the level of assessment desired, the assessments originally included only the soil ingestion contaminant pathway because research by Beyer et al. (1994) and our understanding of contaminant pathways and diet of the three species indicated that soil ingestion can dominate exposure to contaminants. The scientific literature revealed that this is especially true for the owl. The tools used included a custom FORTRAN code, ECORSK3, and a geographic information system (GIS). Following the release of ECORSK3 in FY96, model improvements requested by the U.S. Fish and Wildlife Service (Lusk 1996) and the New Mexico Environment Department (Ford-Schmid 1997) resulted in the production of ECORSK4 and then ECORSK5. The improvements centered on increasing model realism and 
included (1) a bioaccumulation component added to the soil ingestion contaminant exposure pathway, (2) the addition of a food consumption contaminant pathway including a biomagnification component; (3) the option to weight simulated foraging on the basis of distance to nesting or roosting habitats, (4) the option to scale the dimensions of a home range, (5) the option to slope the home range, and (6) the inclusion of a simulated aquatic foraging routine with the ability to vary the ratio of foraging on terrestrial vs. aquatic systems. With these and other more subtle improvements in model input parameters, ECORSK has been revised and the model has been re-executed for the owl and peregrine ecological exposure units (EEUs) (defined later) that originally generated the highest risk indices. The complexity of risk assessment applied was commensurate with a "Stage 1, Tier 2," or preliminary, assessment as defined in the Methods section. This report summarizes the most current results.

Objectives. The primary objectives of the preliminary risk assessment were to

(1) successfully demonstrate the integration of the custom FORTRAN code ECORSK, the LANL Environmental Restoration's contaminant database (Facility for Information, Management and Display - FIMAD) and a GIS,

(2) quantitatively appraise the potential for contaminants (organic, inorganic and radionuclide) to impact threatened and endangered species in or around Los Alamos National Laboratory, and

(3) identify where further assessment is required; this includes identifying known and unknown facets of potential effects to assist in the development of a natural resources management plan.

\section{Methods}

Previous reports (Gallegos et al. 1997a and 1997b; Gonzales et al. 1997) can be consulted for a detailed review of the methods employed. A summary of the methods is made here. The level of risk assessment that we targeted for this study in order to meet the objectives was "Stage 1, Tier 2 " which we define as a preliminary risk assessment in which several elements of risk assessment are addressed:

- Qualitatively evaluate contaminant release, fate, and transport

- Identify contaminants of potential ecological concern (COPECs)

- Identify exposure pathways

- Identify known effects through literature review

- Develop a conceptual model

- Characterize receptors

- Make preliminary estimate of risk

For our intents and purposes, the next stage of assessment ("Stage 2, Tier 2" or "effects assessment") for any species and COPECs that require further study could consist of conducting field studies and performing toxicity tests. A "Tier 3" level of assessment would entail "risk characterization" in which a final risk determination is made, an uncertainty analysis is conducted, and the significance of risks is established. 
The process for conducting the assessments consisted of

- Review Literature. A broad range of literature was reviewed on subjects including but not limited to the biology of the species, home range tendencies, related food webs and diet, population histories, historical relationships with contaminants, and species-specific toxicology.

- Compile Toxicity Reference Values. Toxicity reference values (TRVs) are defined as levels of contaminants below which adverse effects are not expected to occur. The TRVs used in this risk assessment for the nonradiological metals and organics were "no observable adverse effects levels" (NOAELs) as established by various laboratory toxicity tests using organisms ranging from mallard ducks to the lab rat. For the radionuclides, human-based soil screening action levels (SALs) were used as comparison values. A listing of TRVs and SALs that we used as well as a discussion of the uncertainty associated with them may be found in a previous report (Gallegos et al. 1997b).

- Delineate Ecological Exposure Units (EEUs), where EEU = Potential Nesting Habitat + Home Range (foraging area). We define an EEU as an area defined by the biology of a species for which an ecological risk assessment is conducted. EEUs for the three species assessed are shown in Figure 1.

- Grid and Map EEUs. Roughly $75 \%$ of the $43 \mathrm{mi}^{2}$ that make up the Laboratory has been digitized into a personal computer.

- Choose Parameters/Assumptions Considering Objectives, Quotient Method as Summarized Below and other Constraints or Considerations.

$\checkmark F_{S}$ - Fraction of diet made up by soil

$\checkmark$ Forage weighting Function, i.e. $\mathrm{O}_{\mathrm{i}}=\mathrm{e}^{-\mathrm{r} / \mathrm{x}}$

$\checkmark$ Bioaccumulation and biomagnification factors

- Compile Data. This included querying and downloading contaminant data from FIMAD, performing additional queries in data base programs for the inclusion of additional input fields such as background concentrations and TRVs, and structuring this information into ECORSK input files. In total, millions of records were compiled.

- Estimate Risk Using ECORSK.

- Use Modified Environmental Protection Agency Hazard Quotient (HQ) Method to Calculate HQs/HIs for Inorganics, Organics, and Radionuclides for the Soil Ingesiion and Food Consumption Contaminant Pathway.

For the nonradionuclide metals and organics,

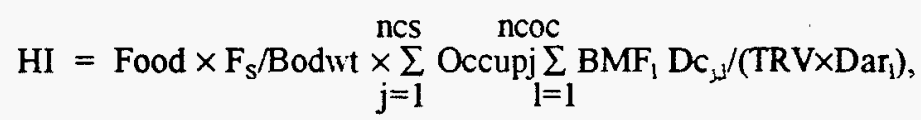




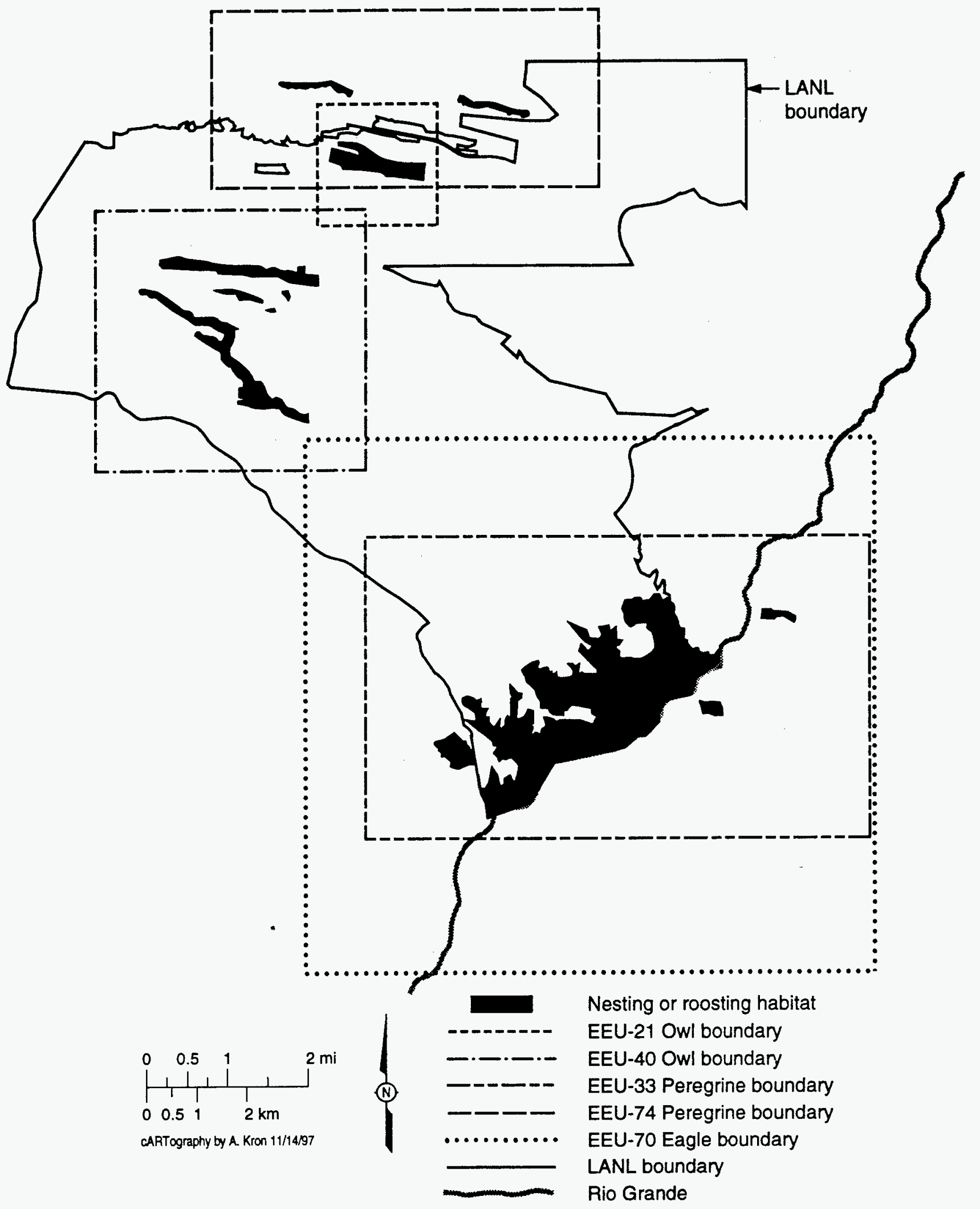

Figure 1. Locations of ecological exposure units (EEUs) for preliminary risk assesment of protected species at the Los Alamos National Laboratory. 


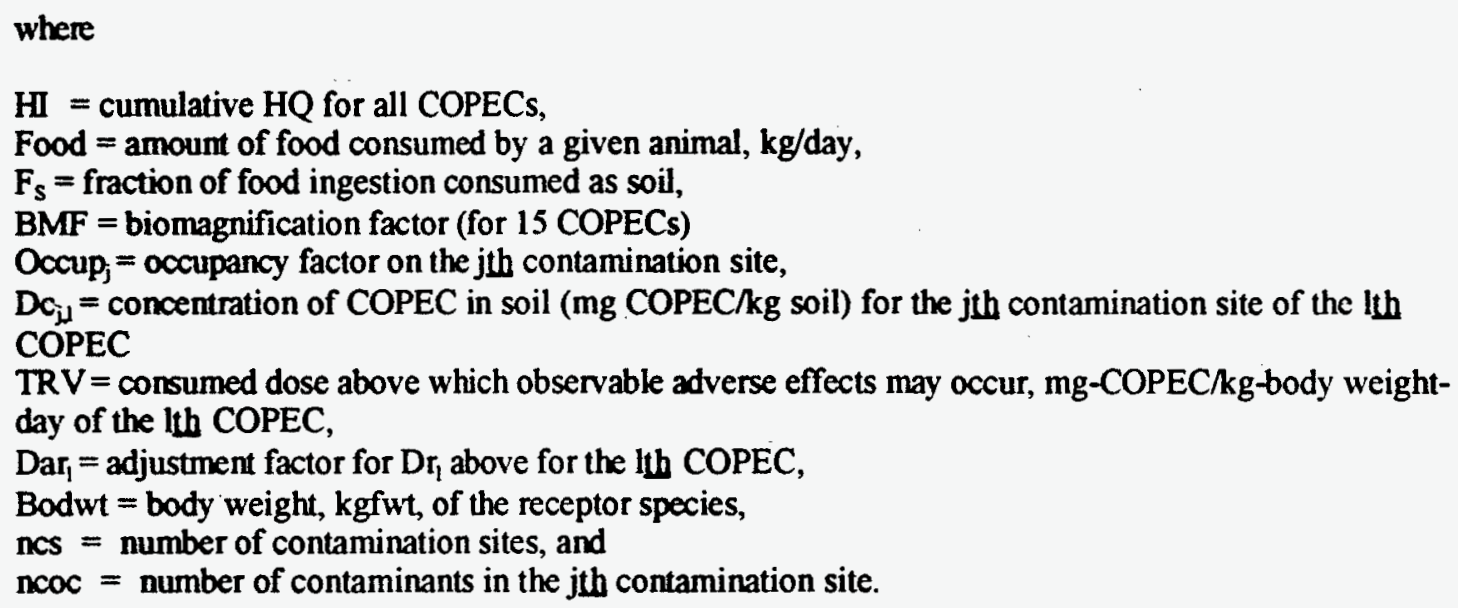

For radionuclides,

$\mathrm{HQc}=\sum_{\mathrm{j}=1}^{\mathrm{ncs}} \mathrm{Occup}_{\mathrm{j}} \sum_{\mathrm{l}=1}^{\mathrm{ncoc}} \mathrm{SC}_{\mathrm{j}, \mathrm{l}} /\left(\mathrm{SAL}_{\mathrm{j}, \ldots} \times \mathrm{SALA}_{\mathrm{j}, \mathrm{L}}\right)$,

where,

$\mathrm{HQc}=$ hazard quotient,

Occup $_{\mathrm{j}}=$ occupancy factor on the jth contamination site,

$\mathrm{SC}_{\mathrm{j}, 1}=$ soil concentration of COPEC, mg-COC/kg-soil for the lith $\mathrm{COC}$ of the jth contamination site,

$\mathrm{SAL}_{\mathrm{j}, \mathrm{l}}=$ soil action level, mg-COPEC/kg-soil for the lth $\mathrm{COC}$ of the jth contamination site,

$\mathrm{SALA}_{\mathrm{j}, \mathrm{l}}=$ adjustment factor for $\mathrm{SAL}_{\mathrm{j}, \mathrm{l}}$ above,

ncs $=$ number of contamination sites, and

ncoc $=$ number of contaminants in the jth contamination site.

- Execute ECORSK for each of the Scenarios shown in the Data Collection Design. Upon randomly selecting a potential nest site (roost site in the case of the eagle) within the defined nesting or roosting habitat of an EEU, ECORSK develops an HR (foraging area) by adding grid cells in a concentric fashion around the nest and calculates an HQ for each COPEC within each 100 - by $100-\mathrm{ft}$ grid cell of the HR. The model repeats this process the number of times specified, which in this case, for a total of 100 simulations. Contaminated grid cells "selected" during one simulation are "replaced" for possible selection during a subsequent simulation, therefore some grid cells are common between any two simulations, but they also have some differences. Thus, the soil contaminant population is not independent from one simulation to another.

The design of data collection is shown in Table A-1 in the Appendix. Two variables were introduced as options in the model as a means of increasing model realism: (1) an option was created that enables weighting of foraging so that occupancy of a species on grid cells for foraging decreases with distance from it nesting or roosting site; thus when foraging is weighted, a species feeds more on grid cells that are close to its nest or roost than grids further from its nest or roost; (2) an option to scale the width-to-height dimensions of the foraging area, or HR, was coded; this 
feature enables the assessor to create foraging area shapes around a nesting or roosting site that mimic hunting patterns that may be determined by factors such as distributions of prey, or considering a population of species the shape and dimensions of the HR for the population collectively may be proportional to the shape of the nesting habitat for the population. Although biomagnification was also treated as a variable at one time in order to measure the sensitivity of the HQ method to this factor, it is not shown in Table A-1. From Table A-1 it can be seen that within a given species and EEU, the number of records in the ECORSK output varied from 1,400 to 25,000 per nest site. The total number of output records for all scenarios, grid cells, and COPECs combined was approximately 301 million.

- Formulate Risk Conclusion. The risk evaluation criteria used for interpreting hazard index results are shown in Table 1.

Table 1. Risk evaluation criteria used to interpret results of applying the EPA Hazard Quotient method (Menzie et al. 1993; EPA 1986).

\begin{tabular}{|c|l|}
\hline Hazard Index Range & Conclusion \\
\hline$<1.0$ & No appreciable impact \\
\hline $1.0-10.0$ & Small potential for impacts \\
\hline $10-100$ & Substantial potential for impacts \\
\hline$>100$ & Ecological impacts very probable \\
\hline
\end{tabular}

- Delineate Further Study Needs and Consider Management Implications. At the level of assessment conducted in this study, any risk conclusions that indicate that some impact is possible generally results only in the recommendation that further study is needed.

\section{Results and Discussion}

EEUs for which there is no new information beyond the results previously reported are not presented; i.e. EEU-40 for the owl and EEU-33 for the peregrine. Tables A-2 through A-4 in the Appendix show the updated results for EEU-21 of the owl, EEU-74 of the peregrine and EEU-70 of the eagle, respectively. Values in Tables A-2 through A-4 are the arithmetic mean of 100 randomly selected nest sites. Only the peregrine had means (three) above the 1.0 risk evaluation criteria (Table A-2). HIs between 1.0 and 10.0 are interpreted as indicating small potential for impacts (Table 1).

For the three peregrine scenarios in which the mean $\mathrm{HI}$ exceeded 1.0, the proportion of 100 nest site HIs that were greater than 1.0 ranged from $52 \%$ to $59 \%$. Although no owl mean HI was above 1.0, two scenarios had individual nest site HIs above 1.0 - the proportion of $100 \mathrm{HIs}$ that was greater than 1.0 was $18 \%$ for one scenario and $35 \%$ for another. The results are considered realistically conservative. The most conservative assumptions are likely that (1) COPECs were assumed to be $100 \%$ available for entrance into biological systems, (2) contamination levels measured at sampling points were assumed for an entire $10,000 \mathrm{ft}^{2}$, (3) human-based TRVs for radionuclides were applied to the threatened and endangered species. 
Since earlier reports on the owl (Gallegos et al. 1997a) and the falcon (Gallegos et al. 1997b), the change perhaps of greatest significance is the inclusion of biomagnification factors in a food consumption contamination pathway. Figure 2 summarizes the influence of biomagnification on mean HI results.

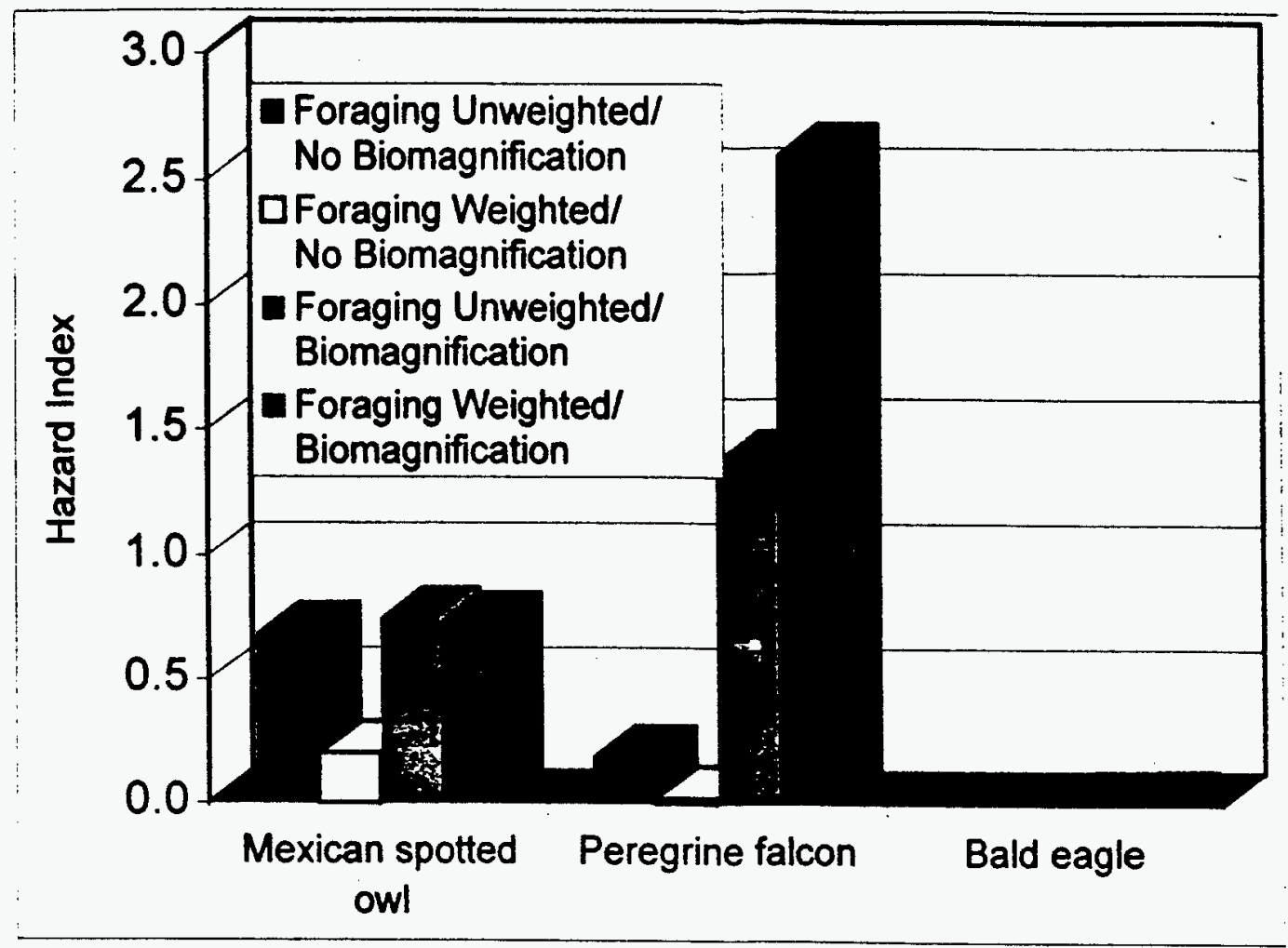

Figure 2. Chart of hazard indices for selected scenarios for the purpose of demonstrating the influence of model realism improvements on risk estimates. Each bar represents the arithmetic mean of 100 randomly located nest sites. Standard error of the mean is listed in Tables A-2 through A-4.

Each bar represents the arithmetic mean of 100 randomly located nest or roost sites. Two of the peregrine means that were greater than 1.0 were cases in which bioaccumulation and biomagnification were factored in and one was not.

Because ECORSK5 partitions risk by COPEC, contributions of individual contaminants to elevated cumulative risk indices can be examined. For the scenario generating the highest $\mathrm{HI}$ for the peregrine, Dichlorodiphenyltrichloroethane (DDT), aroclor-1254 (a polychlorinated biphenyl [PCB]), and dichlorodiphenylethelyne (DDE), a metabolite of DDT, contributed roughly $81 \%$ of the estimated risk.

The results on which the risk conclusion was focused include contributions from background and LANL-related sources considered collectively. It would become important to dwell on the distinction between these two sources of risk if and when mitigation was to become a consideration. This distinction is not relevant from a science perspective. Considering the level of assessment employed in this study (Phase 1 of Tier 2, or preliminary), if a potential for 
adverse impact to a species is identified, then what's important is to identify where further assessment is needed. Nevertheless, there is a valuable and important use for partitioning the portion of total risk contributed by background. If total risk of an appreciable magnitude is estimated for any species and background risk dominates the contribution to that risk, this may be an indication that the risk model may be overly conservative. For the owl, peregrine, and eagle, the proportion of total or unadjusted risk contributed by background was approximately $28 \%, 17 \%$, and $78 \%$, respectively.

\section{Conclusions}

On average, there is a small potential for impact to the peregrine falcon from contaminants at LANL, but no appreciable impact is expected to the spotted owl nor the bald eagle. This conclusion is based on assumptions some of which could have lead to an overestimate of risk and some of which could have lead to an underestimate of risk. Information on risk by specific geographical location was provided, which can be used to maintain risk from contaminants to acceptably low levels by managing contaminated areas, species habitat, facility siting, and facility operations. Additional assessment is needed only on the peregrine.

\section{Literature Cited}

Beyer WN, Conner EE, Gerould S (1994) Estimates of Soil Ingestion by Wildlife. J Wildlife Manage 58(2): 375-382.

EPA (U.S. Environmental Protection Agency) (1986) Standard Evaluation Procedure, Ecological Risk Assessment. Hazard Evaluation Division, EPA-640/0-85-001.

Ford-Schmid R. (1997) Personal communication, R. Ford-Schmid (NM Environment Department) to G. Gonzales (LANL/ESH-20).

Gallegos AF, Gonzales GJ, Bennett KD, Pratt LE (1997a) Preliminary Risk Assessment of the Mexican Spotted Owl under a Spatially-Weighted Foraging Regime at the Los Alamos National Laboratory. Los Alamos National Laboratory report LA-13259-MS.

Gallegos AF, Gonzales GJ, Bennett KD, Pratt LE, Cram DS (1997b) A Spatially-Dynamic Preliminary Risk Assessment of the American Peregrine Falcon at the Los Alamos National Laboratory (Version 1). Los Alamos National Laboratory report LA-13321-MS.

Gonzales GJ, Gallegos AF, Foxx TE, Fresquez PR, Pratt LE, Mullen MA, Gomez PE (1997) Preliminary Risk Assessment of the Bald Eagle at the Los Alamos National Laboratory. Los Alamos National Laboratory report in preparation.

Lusk J (1996) Personal communication, J. Lusk (US Fish and Wildlife Service) to G. Gonzales (LANL/ESH-20). 

Appendix 
Table A-1. Data Collection Design.

Values $(\times 1000)$ are approximate number of observations per nest site.

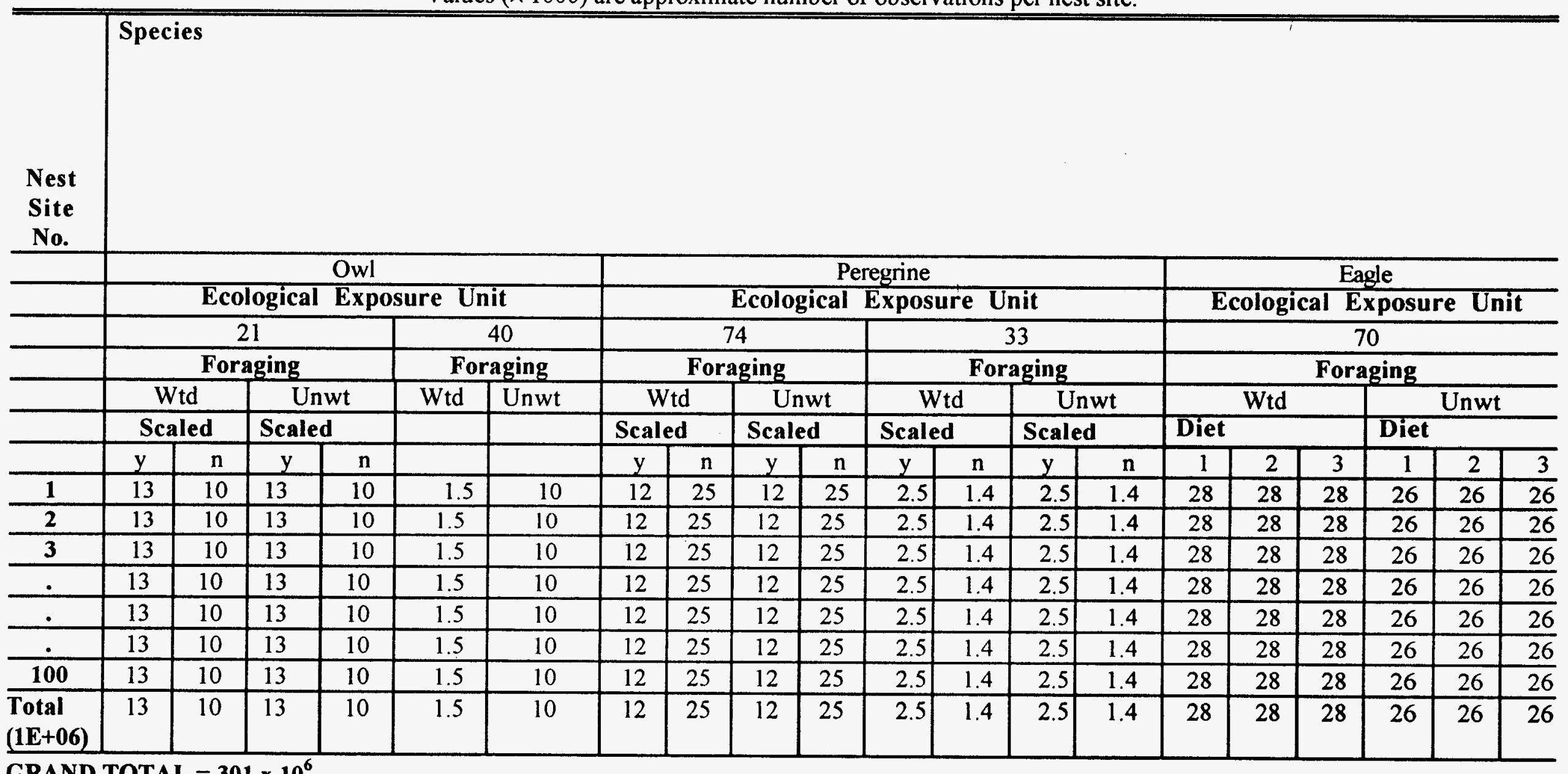


Table A-2. Mean hazard indices (HI) for the Mexican spotted owl, in EEU-21, for various combinations

of forage weighting and home range scaling. Mean $\mathrm{HI}$ values are followed by the mean standard error. The number of observations for each value is 100 .

\begin{tabular}{|c|c|c|c|c|}
\hline \multicolumn{5}{|c|}{ Mexican spotted owl } \\
\hline & \multicolumn{4}{|c|}{ Mean Hazard Index (Cumulative Hazard Quotient) } \\
\hline - & \multicolumn{4}{|c|}{ Contaminant Pathway } \\
\hline Scenario & $\begin{array}{c}\text { Soil } \\
\text { Ingestion }\end{array}$ & $\begin{array}{c}\text { Soil Ingestion } \\
\text { and Food } \\
\text { Consumption } \\
\text { \$ }\end{array}$ & Maximum & Minimum \\
\hline \multicolumn{5}{|l|}{ 1. Home Range Unscaled* } \\
\hline \multicolumn{5}{|c|}{ a. Foraging Unweighted } \\
\hline $\begin{array}{l}\text { Unadjusted Riskt } \\
\text { Background Risk }\end{array}$ & $\begin{array}{l}0.60( \pm 0.061) \\
0.17( \pm 0.019)\end{array}$ & $0.75( \pm 0.088)$ & 0.84 & 0.43 \\
\hline \multicolumn{5}{|l|}{ b. Foraging Weighted $* * *$} \\
\hline Unadjusted Risk & $0.40( \pm 0.16)$ & $0.73( \pm 0.23)$ & 1.12 & $4.8 \mathrm{E}-03$ \\
\hline \multicolumn{5}{|c|}{ 2. Home Range Scaled $* * * * 4: 1$} \\
\hline a. Foraging Unweighted & $\overline{-}$ & & & \\
\hline Unadjusted Risk & $0.69( \pm 0.0+6)$ & $0.87( \pm 5.1 \mathrm{E}-03)$ & 0.68 & 0.86 \\
\hline \multicolumn{5}{|l|}{ b. Foraging Weighted } \\
\hline Unadjusted Risk & $0.70( \pm 0.15)$ & $0.89( \pm 0.21)$ & 1.24 & 0.42 \\
\hline
\end{tabular}

*Unscaled - Refers to a home range with equal border dimensions; i.e., a circle or square.

** Unweighted - Refers to a foraging scheme in which foraging occurs equally throughout a HR.

***Weighted - Refers to a foraging scheme in which foraging is proportional to distance from a nest site; i.e., foraging decreases with distance from the nest site.

****Scaled - Refers to a home range (HR) with unequal border dimensions; i.e., an ellipse or rectangle.

†Unadjusted Risk - Quantified impact associated with sampling within the LANL boundaries. ‡Background risk - Quantified impact associated with "natural" (nonradionuclides) and "regional"

(radionuclides) mean concentrations of COPECs exterior to LANL. 
Table A-3. Mean hazard indices ( $\mathrm{HI})$ for the peregrine falcon for various combinations of forage weighting and home range scaling in EEU-74. Mean HI values are followed by the mean standard error. The number of observations for each value is 100 .

\begin{tabular}{|c|c|c|c|c|c|}
\hline \multicolumn{6}{|c|}{ American peregrine falcon } \\
\hline Scenario & Mean & Hazard Index & mulative Hazar & Quotient & \\
\hline 1. Home Range Unscaled* & \multicolumn{2}{|c|}{ Soil Ingestion Pathway Only } & \multirow{2}{*}{$\begin{array}{c}\text { Food and Soil } \\
\text { Pathways }\end{array}$} & +2 & \multirow{2}{*}{ Min. } \\
\hline a. Foraging Unweighted ${ }^{\star *}$ & & w/BAFs & & Max. & \\
\hline $\begin{array}{l}\text { Unadjusted Risk } \dagger \\
\text { Background Risk } \ddagger\end{array}$ & $\begin{array}{c}0.19( \pm 0.15) \\
0.033( \pm 0.014) \\
\end{array}$ & $0.21( \pm 0.15)$ & $1.16( \pm 1.0)$ & 3.4 & $1.48 \mathrm{E}-(02$ \\
\hline \multicolumn{6}{|l|}{ b. Foraging Weighted ${ }^{* * *}$} \\
\hline Unadjusted Risk & $0.02( \pm 0.07)$ & & $2.60( \pm 2.57)$ & 6.92 & $1.5 \mathrm{E}-4$ \\
\hline \multicolumn{6}{|l|}{ 2. Home Range Scaled $* * * * 4: 1$} \\
\hline \multicolumn{6}{|l|}{ a. Foraging Unweighted } \\
\hline Unadjusted Risk & $0.09( \pm 0.09)$ & & $0.80( \pm 0.29)$ & 1.46 & $1.9 \mathrm{E}-2$ \\
\hline \multicolumn{6}{|l|}{ b. Foraging Weighted } \\
\hline Unadjusted Risk & $2.8 \mathrm{E}-03( \pm 1.3 \mathrm{E}-(03)$ & & $1.14( \pm 1.0)$ & 2.58 & $4.9 \mathrm{E}-5$ \\
\hline
\end{tabular}

*Unscaled - Refers to a home range with equal border dimensions; i.e., a circle or square.

**Unweighted - Refers to a foraging scheme in which foraging occurs equally throughout a HR.

***Weighted - Refers to a foraging scheme in which foraging is proportional to distance from a nest site; i.e., foraging decreases with distance from the nest site.

****Scaled - Refers to a home range (HR) with unequal border dimensions; i.e., an ellipse or rectangle.

†Unadjusted Risk - Quantified impact associated with sampling within the LANL boundaries.

$\ddagger$ Background risk - Quantified impact associated with "natural" (nonradionuclides) and "regional" (radionuclides) mean concentrations of COPECs exterior to LANL. 
Table A-4. Mean hazard indices (HI) for the bald eagle for various combinations of forage weighting, home range shape, and ratio of fish to generic terrestrial food in diet. Mean $\mathrm{HI}$ values are followed by the mean standard error. All values include bioaccumulation for the soil ingestion pathway and biomagnification for the food consumption pathway.

\begin{tabular}{|c|c|c|c|}
\hline \multirow{4}{*}{ Scenario } & \multicolumn{2}{|l|}{ Bald Eagle } & \\
\hline & \multicolumn{3}{|c|}{ Mean Hazard Index (Cumulative Hazard Quotent) } \\
\hline & \multicolumn{3}{|c|}{ Diet* } \\
\hline & $90 \%$ fish & $75 \%$ fish & $50 \%$ fish \\
\hline \multicolumn{4}{|l|}{ 1. Home Range Unscaled ${ }^{* *}$} \\
\hline \multicolumn{4}{|c|}{ a. Foraging Unweighted ${ }^{\star \star \star}$} \\
\hline Unadjusted RiskŨ & $3.2 \mathrm{E}-03( \pm 3.4 \mathrm{E}-4)$ & $5.8 \mathrm{E}-03( \pm 7.5 \mathrm{E}-4)$ & $1.2 \mathrm{E}-2( \pm 1.9 \mathrm{E}-03)$ \\
\hline Background Riská & $2.5 \mathrm{E}-03( \pm 3.0 \mathrm{E}-4)$ & & \\
\hline \multicolumn{4}{|l|}{ 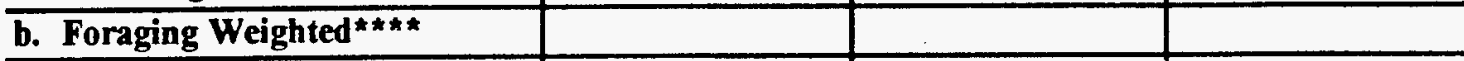 } \\
\hline Unadjusted Risk & $3.7 \mathrm{E}-3( \pm 6.5 \mathrm{E}-04)$ & $6.9 E-3( \pm 1.8 E-03)$ & $1.5 \mathrm{E}-2( \pm 4.4 \mathrm{E}-03)$ \\
\hline
\end{tabular}

\begin{tabular}{l|l|l|l}
\hline 2. Home Range Scaled & & & \\
\hline a. Foraging Unweighted & & & \\
\hline Unadjusted Risk & $3.2 \mathrm{E}-03( \pm 3.2 \mathrm{E}-04)$ & $5.9 \mathrm{E}-3( \pm 7.6 \mathrm{E}-04)$ & $1.3 \mathrm{E}-02( \pm 1.9 \mathrm{E}-03)$ \\
\hline b. Foraging Weighted & & & \\
\hline Unadjusted Risk & $3.6 \mathrm{E}-03( \pm 8.2 \mathrm{E}-04)$ & $6.9 \mathrm{E}-03( \pm 2.2 \mathrm{E}-03)$ & $1.5 \mathrm{E}-02( \pm 5.0 \mathrm{E}-03)$ \\
\hline
\end{tabular}

*Includes a biomagnification component.

**Unscaled - Refers to a home range with equal border dimensions, i.e. a circle or square.

***Unweighted - Refers to a foraging scheme in which foraging occurs equally throughout a HR.

****Weighted - Refers to a foraging scheme in which foraging is proportional to distance from a nest site; i.e. foraging decreases with distance from the nest site.

*****Scaled - Refers to retangular shaped home range (HR) with a width to height ratio of 2.6. ÜUnadjusted Risk - Quantified impact associated with sampling within LANL boundaries.

á Background Risk - Quantified risk associated with "natural (nonradionuclides) and "regional" (radionuclides) mean concentrations of COPECs exterior to LANL. 


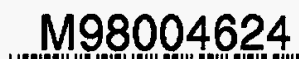

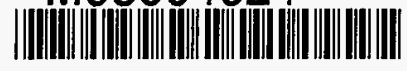

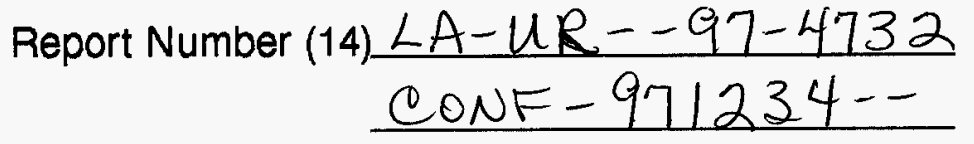

Publ. Date (11)

Sponsor Code (18)

$\frac{199802}{D O E / M A}, X F$

UC Category (19)

UC-90Q, DOE/ER 